\title{
Produção no moddle de hipertextos para ensino do eletromagnetismo do motor elétrico
}

Hypertext production on moddle to the teaching of the electromagnetism of the motor electric

\author{
Ricardo Barreto da Silva' \\ IDepartamento de Física - Universidade Federal de Santa Maria. e-mail: rbarretol975@gmail.com
}

\section{Resumo}

Este artigo descreve a produção no ambiente virtual de aprendizagem MOODLE de hipertextos para o estudo dos fenômenos eletromagnéticos necessários à compreensão do funcionamento do motor elétrico. Foram produzidos três hipertextos contendo palavras e expressões conectadas com páginas da web que podem ser livremente acessadas de forma não-linear e rápida. Os resultados preliminares demonstram a potencialidade da web como fonte de objetos educacionais e do MOODLE como instrumento de gerenciamento e produção de hipertextos para o ensino de física.

Palavras Chave: hipertexto, hipermídia, MOODLE, eletromagnetismo, objetos educacionais, ensino de física, motor elétrico, ensino a distância, ambientes virtuais de aprendizagem.

\begin{abstract}
This paper describes the production by MOODLE of hypertexts for the study of electromagnetic phenomena necessary for understanding the operation of the electric motor. Were produced three hypertext with words and expressions connected to web pages which can be quickly and randomly accessed. The preliminary results demonstrate the potential of the web as a source of learning objects and MOODLE as a tool for management and production of hypertexts for teaching physics.
\end{abstract}

Keywords: hypertext, hypermedia, MOODLE, electromagnetism, learning objects, physics education, electric motor, distance learning, virtual learning environments. 


\section{INTRODUÇÃO}

Recentemente, o Conselho Nacional de Educação (CNE) publicou o relatório "Escassez de Professores no Ensino Médio: Propostas Estruturais e Emergenciais" ${ }^{1}$, o qual foi produzido para estudar medidas que visem superar a falta de docentes no Ensino Médio. A principal conclusão no relatório é que o décit de professores tenderá a ampliar-se nos próximos anos, a menos que ações emergenciais sejam implantadas. Dados do INEP ${ }^{2}$ apontam para a necessidade de $235 \mathrm{mil}$ professores para o Ensino Médio, principalmente nas disciplinas de Física, Química, Matemática e Biologia. Seriam necessários, por exemplo, 55 mil professores de Física, porém, entre 1990 e 2001 as universidades brasileiras formaram apenas 7.216 professores de Física. Entre as proposições apresentadas no relatório com vistas a solucionar o problema consta que as políticas públicas devem priorizar a formação de professores de Física, Química, Matemática e Biologia. Para isso, entre outras ações, o país precisará ampliar a oferta de cursos de licenciatura à distância ${ }^{3}$.

Neste sentido, dentre os projetos idealizados pelo MEC se destaca o sistema Universidade Aberta do Brasil (UAB), lançado em dezembro de 2005. O programa, integrado por universidades públicas brasileiras, busca democratizar, expandir e interiorizar a oferta de ensino superior público e gratuito por meio da educação à distância, e sua prioridade é oferecer formação inicial a professores sem graduação da rede pública de educação básica, bem como formação continuada aos graduados ${ }^{4}$.

$\mathrm{Na}$ Universidade Federal de Santa Maria, as atividades da UAB estão vinculadas ao Núcleo de Tecnologia Educacional (NTE), órgão responsável por dar apoio técnico aos cursos de graduação, pós-graduação e extensão na modalidade $\mathrm{EAD}$, promover a pesquisa sobre tecnologias educacionais e instrumentos de ação em rede e produzir e disseminar ferramentas tecnológicas para a utilização didático-pedagógica ${ }^{5}$. Atualmente, o sistema UAB/UFSM oferece sete cursos de graduação e oito de pós-graduação, contando com 36 pólos de apoio presencial no Rio Grande do Sul, dois no Paraná, um em São Paulo e um no Tocantins. Entre os cursos de graduação, a UAB/UFSM disponibiliza o curso de Licenciatura em Física, com dez pólos de apoio no interior Rio Grande do Sul e um no interior de São Paulo ${ }^{6}$. De acordo com o seu projeto pedagógico, o objetivo principal deste curso é formar professores aptos para atuar na educação básica e/ou enfrentar um curso de pós-graduação em ensino de Física ${ }^{7}$.

O presente trabalho, desenvolvido entre maio de 2012 e fevereiro de 2013, diz respeito a um dos projetos selecionados pelo NTE no âmbito do edital (17/2012) de seleção de projetos para pesquisa, desenvolvimento e capacitação no Núcleo UAB/UFSM, na linha temática recursos educa-

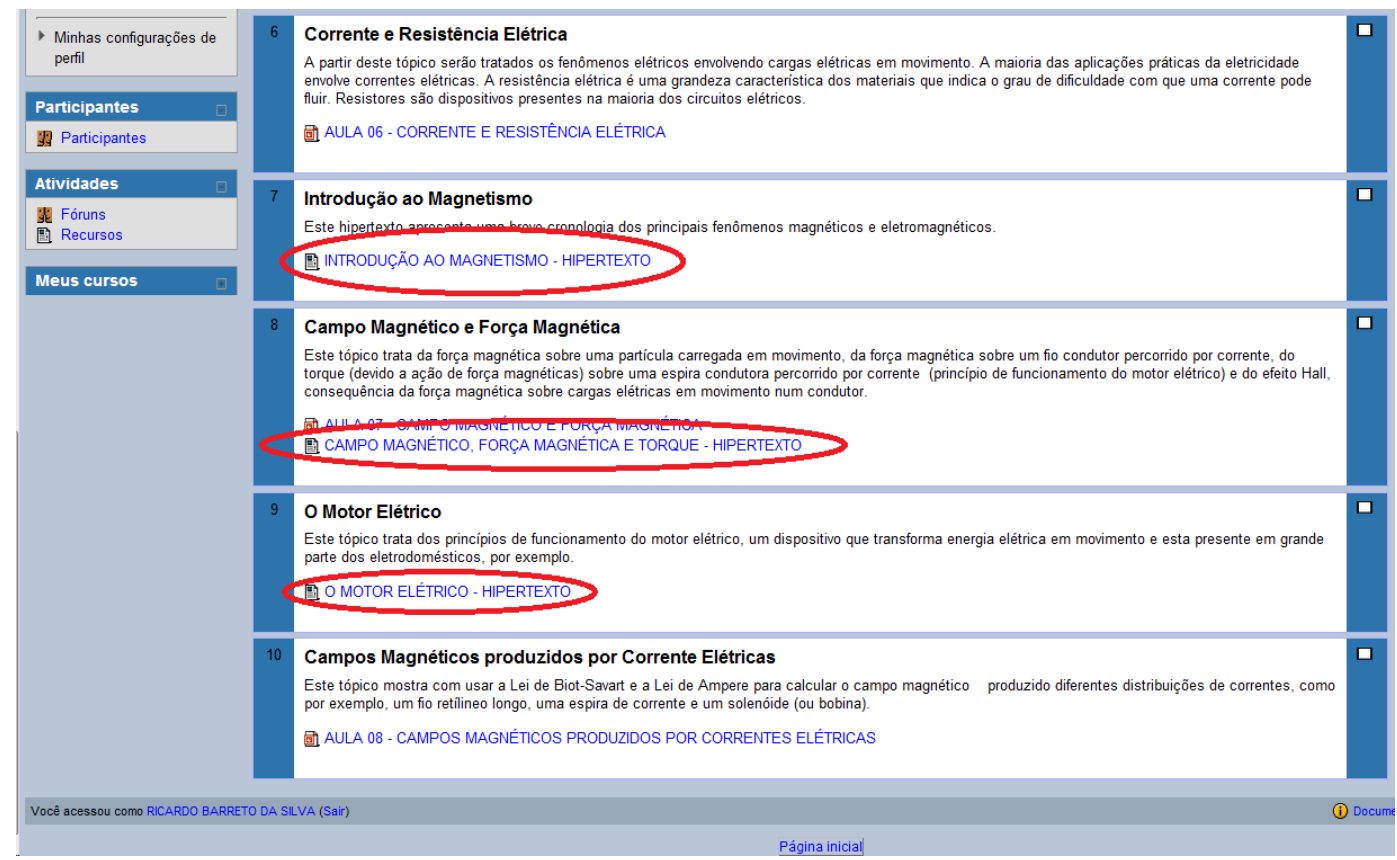

Figura 01 - Imagem da página principal no MOODLE do curso de Física III, criada pelo autor no segundo semestre de 2012. Circulado em vermelho estão destacados os links para os hipertextos. 
cionais para o ambiente virtual de aprendizagem MOODLE. O objetivo foi produzir, usando os recursos do MOODLE, hipertextos para o ensino dos fenômenos fundamentais do eletromagnetismo, tendo como tema gerador o princípio de funcionamento dos motores elétricos. Foram produzidos três hipertextos nos quais os conceitos e proposições fundamentais do eletromagnetismo foram ligados a páginas da web de acesso livre. Essas páginas contêm objetos educacionais tais como textos, vídeo aulas, documentários, vídeos de demonstrações experimentais, animações e simulações virtuais. Os hipertextos foram incluídos como tópicos de um curso básico de eletromagnetismo, ofertado no segundo semestre de 2012 no Departamento de Física da UFSM, no qual a plataforma MOODLE foi utilizada como ferramenta de apoio. Os conteúdos abordados foram organizados em tópicos conforme mostra a imagem na figura 01 .

\section{O COMPUTADOR NO ENSINO DE FÍSICA}

Atualmente o uso de computadores é uma pratica comum em todas as áreas do conhecimento, inclusive no ensino de Física. De acordo com Rezende (2001, p.198) ${ }^{8}$

O uso do computador no ensino de física pode ser significativo quando usado como um meio que proporcione a construção do conhecimento do estudante a partir do que ele já sabe; que o ajude a reestruturar e reorganizar seus conceitos quando necessário; que possibilite a relação com fenômenos do seu cotidiano e que ofereça um ambiente estimulante ao seu esforço de raciocinar e de aprender.

Em recente revisão sobre o tema, Fiolhais \& Trindade ${ }^{9}$ dividiram a evolução do uso do computador no ensino em três períodos que acompanharam as principais teorias de aprendizagem. Segundo esses autores, a primeira geração foi moldada pela teoria behaviorista, segundo a qual a mente responde a estímulos que podem ser observados e medidos. A segunda geração foi moldada pela teoria cognitiva segundo a qual as mudanças no comportamento do aluno podem ser tomadas como indicadores dos processos em desenvolvimento na sua mente. Essa geração enfatizou a forma de apresentação tanto quanto os conteúdos. O pressuposto de que não há dois alunos psicologicamente iguais conduziu a consideráveis melhorias na utilização dos computadores. Os avanços tecnológicos da década de noventa influenciaram o aparecimento de uma terceira geração baseada na teoria construtivista, segundo a qual o aluno constrói a sua visão do mundo através das suas experiências individuais. Essa geração caracteriza-se pela ênfase nas interações entre aluno e máquina e considera a natureza dessas interações tão importante quanto o conteúdo de informação ou a forma como este é apresentado. O meio de trabalho mais utilizado passou a ser a Internet e a forma de apresentação da informação passou a ser predominantemente o hipertexto, formato que permite ao aluno escolher o seu percurso de acordo com seus interesses e suas necessidades.

Para estes autores (ibid), as principais modalidades de uso dos computadores no ensino de Física são: (i) aquisição de dados por computador, (ii) modelagem e simulação, (iii) materiais multimídia, (iv) realidade virtual e (v) busca de informações na internet. Segundo Boyce ${ }^{10}$ (apud Fiolhais \& Trindade), o termo multimídia significa que um programa pode incluir uma variedade de elementos, como textos, sons, imagens, simulações e vídeos, e materiais multimídia são baseados no conceito de hipertexto, ou de forma mais abrangente, no conceito de hipermídia. As características essenciais desse tipo de material didático são a interatividade e a flexibilidade de escolha do caminho a seguir. A multimídia pode ser utilizada on-line ou off-line, de acordo com o lugar onde a informação é armazenada, na Internet ou em disco móvel (CD-ROMs, DVDs, etc...).

Recentemente, Araujo \&Vait ${ }^{11}$ mapearam os trabalhos envolvendo o uso do computador no ensino de Física, em artigos publicados nas principais revistas da área entre 1999 e 2003, identificando as modalidades pedagógicas e os conteúdos de Física escolhidos como tema. Os 109 artigos encontrados foram classificados em sete categorias de acordo com os diferentes modos de aplicação do computador: (i) instrução e avaliação mediada pelo computador, (ii) modelagem e simulação computacional, (iii) coleta e análise de dados em tempo real, (iv) recursos multimídia, (v) comunicação à distância, (vi) resolução algébrica/numérica e (vii) estudo de processos cognitivos. Levando em conta o número total de publicações nessas revistas, a produção na área pode ser considerada pequena. O estudo mostrou que os trabalhos estão concentrados em tópicos relacionados à mecânica newtoniana, abordada majoritariamente por meio da modelagem e simulação. Também é surpreende que apenas 13 artigos tenham sido classificados na categoria recursos multimídia e que nenhum deles aborda o eletromagnetismo como tema de 
investigação. Esses resultados indicam que materiais do tipo hipertexto e hipermídia ainda são pouco explorados na pesquisa relativa ao uso de tecnologias computacionais no ensino de física e que esta área é um tema pouco explorado na pesquisa em ensino de física.

É importante perceber que nos trabalho acima mencionados, os termos multimídia, hipertexto e hipermídia são utilizados para designar materiais didáticos digitais interativos. A conceituação desses termos ainda hoje é objeto de discussão. Para alguns autores ${ }^{12,13}$, a hipermídia é vista como a intersecção entre o hipertexto e a multimídia, considerando que o hipertexto é um sistema onde a informação aparece na forma de texto organizada não sequencialmente através de ligações entre palavras-chave e que sistemas multimídia são caracterizados por múltiplas formas de representação da informação: texto, imagem áudio, vídeo, etc.

De acordo com Lévi ${ }^{14}$, o termo multimídia significa aquilo que emprega diversos suportes ou diversos veículos de comunicação e vem sendo usado erroneamente quando se trata da multimodalidade e da integração digital da informação. A multimodalidade se refere às diferentes formas da informação tratada pelos computadores, que inclui dados numéricos, textos, sons e imagens, de forma que seria mais correto, de um ponto de vista linguístico, falar de informações ou mensagens multimodais. O termo é inadequado, por exemplo, para designar um DVD usado para suportar um programa educativo, que seria mais corretamente definido como um documento multimodal interativo de suporte digital ou, simplesmente, um hiperdocumento. O termo é corretamente empregado quando, por exemplo, o lançamento de um filme ocorre simultaneamente ao lançamento de um vídeo-game, de uma série de televisão, de camisetas e brinquedos, neste caso, se estaria de fato frente a uma estratégia multimídia. No ambiente de ensino, para serem caracterizadas como multimídia, as experiência educacionais necessitam exigir tanto a interatividade quanto a pluralidade de suportes e veículos de informação (livro, jornal, rádio, televisão, Internet, computador, notebook, DVD, CD-ROM, projetor, lousa eletrônica, quadro negro, etc.). Assim, quando o termo multimídia é utilizado em um contexto em que ele não parece designar um tipo particular de suporte é necessário atribuir ao enunciador à intenção de designar um horizonte de unimídia multimodal, uma estrutura de comunicação integrada, digital e interativa.

Ainda de acordo com Lévy, um hipertexto é um texto em formato digital composto por blocos elementares ligados por links, uma rede de associações complexas entre sons, imagens e textos que pode ser explorada em tempo real. Assim, para este autor, um hipertexto digital pode ser definido como conjuntos de informações multimodais disposta em uma rede de navegação rápida e intuitiva (ibid).

Por outro lado, ele aponta que um sistema hipermídia seria um desenvolvimento do hipertexto que integra texto com imagens, vídeos e sons, geralmente vinculados entre si de forma interativa $^{15}$. Uma enciclopédia em DVD seria um exemplo clássico de hipermídia. Apesar das definições distintas, há uma tendência de fusão desses conceitos, visto que os hipertextos hoje já incorporam os elementos gráficos sofisticados que caracterizam o documento hipermídia ${ }^{16}$ (apud Heckler et al. ${ }^{17}$ )

\section{MOODLE}

Nos últimos 20 anos, o rápido desenvolvimento das TIC abriu novas perspectivas para a veiculação eletrônica de disciplinas e cursos acadêmicos. Entretanto, o uso de tecnologias não é garantia de inovação pedagógica e o uso do computador ainda carece de modelos pedagógicos, ferramentas de ensino e materiais educacionais adequados à modalidade. O modelo de ensino informatizado mais difundido atualmente é o e-learning, ou ensino eletrônico, baseado em sistemas de gestão da aprendizagem, ou ambientes virtuais de aprendizagem, softwares que auxiliam na montagem de cursos acessíveis pela Internet. São aplicações projetadas para funcionar como salas de aula virtuais, gerando várias possibilidades de interação entre os seus participantes ${ }^{18}$.

O MOODLE (Modular Object Oriented Distance Learning) é o ambiente virtual de aprendizagem que vem sendo utilizado pelas universidades públicas brasileiras, principalmente em cursos a distância, como apoio a cursos presenciais e na formação de grupos treinamento de professores e técnicos em educação. Ele é um programa livre, desenvolvido de forma colaborativa por uma comunidade virtual que reúne programadores de diferentes nacionalidades e evolui continuamente de acordo com as necessidades de seus usuários. É considerado um programa de fácil utilização, que pode dar origem tanto a página de uma disciplina, com dezenas de participantes, como à página de uma universidade, com milhares de usuários. Foi originalmente desenvolvido para administração de atividades educacionais de natureza sócio-construtivista, por isso oferece ferramentas administrativas, 
acadêmicas e de comunicação que facilitam consideravelmente a interação entre os participantes de uma comunidade virtual. Em linguagem coloquial em língua inglesa, o verbo "to moodle" descreve o processo de navegar despretensiosamente por algo enquanto se faz outras coisas ${ }^{19}$.

Basicamente o MOODLE permite três formatos de curso: social, semanal e modular. $\mathrm{O}$ social foi idealizado para cursos abertos que não seguem uma sequência estruturada de conteúdos e atividades. O semanal e o modular são adequados para produção de cursos estruturados, centrados em conteúdos e atividades pré-concebidas. A escolha do formato depende da proposta pedagógica do curso ${ }^{20}$.

Entre os recursos do MOODLE, é importante ressaltar a possibilidade de acrescentar aos módulos arquivos, páginas web, capítulos de livro e rótulos, textos simples usados para organizar os tópicos e agrupar atividades por tipo ${ }^{21}$. Nesse trabalho, foi explorada a possibilidade de criação de hiperdocumentos (hipertextos) através da ferramenta que permite criação de páginas web e a inserção de links, para sites ou arquivos privados, durante a edição do texto principal associado á página.

\section{TEMATICA ABORDADA}

Os Parâmetros Curriculares Nacionais para o Ensino Médio (PCN) apresentam as competências a serem desenvolvidas pela física com o objetivo de superar as práticas tradicionais, que tratam a física de maneira desarticulada do mundo vivido pelo aluno e pelo professor. $\mathrm{O}$ documento sugere o desenvolvimento de "conhecimentos práticos, contextualizados, que respondam às necessidades da vida contemporânea, e o desenvolvimento de conhecimentos mais amplos e abstratos, que correspondem a uma cultura geral e a uma visão de mundo". Ressaltam que um dos pontos de partida seria o mundo vivencial dos alunos, da escola e da comunidade, pois o que se pretende é o desenvolvimento de competências e habilidades com vistas às intervenções e julgamentos práticos ${ }^{22}$.

Os PCN+ (orientações educacionais complementares aos parâmetros curriculares nacionais) retomam a importância da contextualização ao afirmarem que "as competências em física para a vida são construídas em um presente contextualizado, em articulação com competências de outras áreas". A física seria, portanto, um meio e não um fim, e passa a ser vista como um instrumento para a compreensão do mundo. De outra parte, há um reconhecimento nesse documento deque não existe uma receita pronta para a transposição dessas proposições em práticas escolares concretas ${ }^{23}$.

Por outro lado, ao propor uma abordagem temática, os $\mathrm{PCN}+$ (ibid) ressaltam que a principal intenção da estratégia didática apoiada em temas estruturadores se sustenta na crença de que "os temas de trabalho, na medida em que articulam conhecimentos e competências, transformam-se em elementos estruturadores da ação pedagógica". Com vistas a oferecer subsídios para a organização dos conteúdos a ensinar, o documento sugere seis temas estruturadores para o ensino de física: (i) Movimento, variações e conservações, (ii) Calor, ambiente e usos de energia, (iii) Som, imagem e informação, (iv) Equipamentos elétricos e telecomunicações; (v) Matéria e radiação e (vi) Universo, Terra e Vida. Cada tema foi subdividido em unidades temáticas. O tema (iv) inclui as unidades temáticas: aparelhos elétricos, motores elétricos, geradores, emissores e receptores, o que justifica a escolha do motor elétrico como tema estruturador para a organização dos conteúdos de eletromagnetismo abordados neste trabalho.

De um ponto de vista histórico, a conexão entre a eletricidade e o magnetismo se estabeleceu a partir da observação empírica de que cargas elétricas em movimento produzem efeitos magnéticos. De outra forma, um condutor percorrido por corrente elétrica produz efeitos magnéticos de forma similar a um imã. Por exemplo, uma espira circular condutora percorrida por corrente apresenta pólos magnéticos norte e sul e pode defletir a agulha magnética de uma bússola. As interações magnéticas entre imãs, atração ente pólos diferentes e repulsão entre pólos similares, é o princípio básico de funcionamento de um motor elétrico, dispositivo que transforma energia elétrica em energia cinética (movimento). Dentro de um motor elétrico essas forças de atração e repulsão criam o movimento de rotação. Os motores elétricos são basicamente compostos por um eletroímã (rotor) que gira ao interagir com um imã natural fixo (imã de campo). Um eixo ligado ao rotor transmite o movimento de rotação a um sistema mecânico como as hélices de um ventilador ou as rodas de um carro.

A interação entre elementos magnéticos é mediada pelo campo magnético, entidade física existente em torno de imãs ou condutores percorridos por corrente. Geometricamente, o campo magnético é representado como um campo vetorial, ou seja, em cada ponto do espaço em torno de um elemento magnético, ele é descrito por um vetor com certa magnitude, direção e sentido. A 
definição do vetor campo magnético deriva do fato de que partículas carregadas em movimento num campo magnético podem ser defletidas por uma força magnética. $\mathrm{O}$ vetor campo magnético num ponto do espaço é definido em termos da força magnética que age sobre uma partícula eletricamente carregada quando ela passa por este ponto e da velocidade da partícula. A relação entre a força magnética $\left(\vec{F}_{m}\right)$, a velocidade da partícula $(\vec{v})$ e o campo magnético $(\vec{B})$ pode ser descrita pela equação $\vec{F}_{m}=q \vec{v} \times \vec{B}$, na qual $q$ representa a carga da partícula. De acordo com esta equação, a força magnética é proporcional ao produto vetorial entre a velocidade e o campo magnético de forma que a força e o campo magnético são sempre ortogonais. Além disso, se a partícula se deslocar na direção do campo magnético, a força será nula e ela não será defletida. Uma corrente elétrica consiste de cargas elétricas em movimento no interior de um material. Logo, quando um fio condutor percorrido por corrente é colocado numa região de campo magnético a força sobre as cargas em movimento são transmitidas para o fio que será defletido. No caso de um campo magnético uniforme, a força magnética sobre um fio retilíneo de comprimento $\ell$ percorrido por uma corrente $i$ é descrita pela e quação $\vec{F}_{. .}=\overrightarrow{i \ell} \times \vec{B}$, onde o vetor $\vec{\ell}$ tem a direção da corrente e o módulo igual ao comprimento do fio. Esta equação permite uma definição alternativa para o campo magnético, em termos da força magnética sobre um fio com corrente, mais útil de um ponto de vista experimental. O torque (grandeza associada à energia de rotação) sobre uma espira condutora retangular percorrida por corrente que interage com um campo magnético uniforme, calculado com a aplicação equação anterior, pode ser escrito como $\vec{\tau}=i A \times B$, onde $i$ é a corrente na espira e o vetor $\vec{A}$ tem a direção da reta normal ao plano da espira e módulo igual à área da espira.

As ideias acima expostas podem ser resumidas na seguinte proposição: um imã produz um campo magnético que interage com outro imã produzindo uma força magnética e consequentemente movimento. Do ponto de vista da Teoria da aprendizagem significativa, de acordo com o princípio da diferenciação progressiva, segundo o qual as ideias mais gerais devem ser apresentadas no inicio da instrução e periodicamente retomadas possibilitando sua progressiva diferenciação ${ }^{24}$, a partir dessa proposição geral, outras mais específicas devem ser exploradas numa atividade educacional voltada para o ensino do eletromagnetismo.

\section{OBJETOS EDUCACIONAIS}

A quantidade de material paradidático disponível na Internet é muito grande. Entretanto, na maioria dos casos a qualidade deixa a desejar, principalmente no que diz respeito à precisão de linguagem, o que torna a seleção deste material uma atividade bastante demorada e complexa. Em termos de vídeos, a página mais abundante é a do Youtube (www.youtube.com). Lá se encontram aulas sobre diversos temas de matemática e física, documentários históricos, biográficos e educacionais, bem como, simulações e demonstrações empíricas de fenômenos físicos. Além do Youtube, foram usados links para a pagina do Grupo de Ensino de Física (GEF) da UFSM (www.ufsm.br/ gef/), que disponibiliza uma série de cadernos de física, em formato digital, escritos com alto rigor linguístico, para a pagina da Fundação Lemann (www.fundacaolemann.org.br), que está traduzindo para o português os vídeos da Khan Academy (www. khanacademy.org ), organização não governamental que disponibilizadas vídeo aulas gratuitamente pela Internet, para o site ComoTudoFunciona (www. hsw.uol.com.br), que disponibiliza milhares de artigos escritos num bom nível, com explicações para os mais variados temas, incluindo dispositivos tecnológicos e fenômenos naturais, e para páginas da Wikipédia (www.wikipedia.org), uma enciclopédia online de acesso livre. Embora seja uma das fontes de informação mais abundantes da Internet, a utilização da Wikipédia exige cautela, visto que os hipertextos são escritos de forma colaborativa por usuários do mundo todo, o que não garante a precisão de linguagem adequada aos padrões aceitos pela comunidade científica. Apesar do grande número de possibilidades, pela necessidade de material de qualidade e pelo tempo limitado para a execução do projeto optou-se pela utilização das cinco páginas web acima mencionadas como fonte de objetos educacionais.

\section{Desenvolvimento dos hipertextos}

No que se refere ao uso de hipertextos nos processos de aprendizagem, de acordo com Morgado $^{25}$, é necessário reflexão sobre se existem de fato vantagens reais. Neste sentido, ela aponta que a literatura especializada é contraditória em relação à questão, embora seja consenso a opinião de que o hipertexto possibilita a criação de ambientes em que o usuário experimenta certo grau de autonomia 
enquanto navega na informação, fato que contribui significativamente para o afloramento de estratégias individuais de aprendizagem. Outras vantagens foram apontadas referentes ao uso do hipertexto ${ }^{26}$ (apud Morgado): permitir diferentes níveis de conhecimento prévio; encorajar a exploração; permitir a visualização de sub-tarefas como parte de tarefas mais globais e adaptar as informações aos estilos individuais de aprendizagem.

A utilização de animações, vídeos e simuladores possibilita que os conteúdos sejam apresentados em múltiplas representações, complementando as ideias contidas nos textos e imagens estáticas e potencializando as possibilidades de associações entre os conceitos na estrutura cognitiva do aluno. $\mathrm{O}$ uso destas diferentes formas de representação também serve de estímulo aumentando a predisposição a aprender do indivíduo, mobilizando além de aspectos cognitivos, fatores de ordem emocional $^{27}$ (apud Machado \& $\mathrm{Nardi}^{28}$ ).

$\mathrm{Na}$ produção de um hipertexto para fins educacionais, Morgado (ibid) salienta a importância de considerar os princípios resultantes da investigação sobre processos de aprendizagem. À luz do que se sabe hoje, a aprendizagem se processa por meio de relações entre o novo conhecimento e aquele que o aluno já detém. Por isso, a importância de que a concepção do hipertexto seja orientada, por exemplo, por conceitos como o de organizadores prévios de Ausubel, segundo o qual um conjunto de preposições de caráter mais geral e inclusivo, que orientem e estruturem a aprendizagem, deve ser enunciado antes da introdução do novo material ${ }^{29}$. O conhecimento prévio de um aprendiz depende da sua estrutura cognitiva, diz respeito ao conteúdo e à organização de suas ideias. Assim, como recurso pedagógico, numa situação de ensino-aprendizagem pode ser necessário à utilização de organizadores prévios, ou seja, de materiais introdutórios de natureza mais geral, que servem para mostrar as possíveis relações entre o novo conhecimento e o conhecimento prévio.

Nesse trabalho, a palavra texto foi tomada em seu sentido mais amplo, que não exclui nem sons nem imagens ${ }^{16}$. A estrutura dos hipertextos foi projetada para proporcionar conexões entre conceitos, de forma a induzir à formação de significados relevantes para o estudante, segundo princípios construtivistas da aprendizagem significativa de Ausubel. Resumidamente, ela pode ser definida como um processo progressivo, que ocorre à medida que os significados de novos conhecimentos vão sendo captados e internalizados pela estrutura cognitiva preexistente no cérebro do aprendiz. Ela depende essencialmente dos conhecimentos prévios, da predisposição a aprender do indivíduo e de unidades de estudo potencialmente significativas $^{24}$. Uma possibilidade operacional é identificar conhecimentos que possivelmente são comuns ao grupo de alunos. No caso do eletromagnetismo, é razoável supor que grande parte dos alunos de uma turma, seja na graduação ou no nível médio, conhece o fato de que imãs interagem com imãs, e está é à ideia central por traz do funcionamento de um motor elétrico a partir da qual uma unidade de ensino potencialmente significativa deve ser planejada.

Algumas competências específicas a serem desenvolvidas no estudo dos motores elétricos foram apontadas nos $\mathrm{PCN}+$ : compreender os fenômenos magnéticos para explicar o magnetismo terrestre, o campo magnético de um ímã, a magnetização de materiais ferromagnéticos e a inseparabilidade dos pólos magnéticos; reconhecer a relação entre fenômenos magnéticos e elétricos para explicar o funcionamento de motores elétricos, geradores e transformadores de energia e conhecer critérios que orientem a utilização de aparelhos elétricos como, por exemplo, gastos de energia, eficiência, riscos e cuidados ${ }^{24}$.

Os princípios pedagógicos e as competências associadas ao ensino de física, acima descritas, orientaram a estruturação dos conteúdos nos hipertextos produzidos. Todo material foi desenvolvido para ser disponibilizado no MOODLE/UFSM para estudantes e professores. O desenvolvimento englobou as seguintes etapas: revisão bibliográfica, seleção dos tópicos de eletromagnetismo associados ao motor elétrico, pesquisa sobre os recursos educacionais disponíveis na Internet, adaptação do texto principal de cada hipertexto, estudo dos recursos do MOODLE, associação dos objetos educacionais selecionados a cada hipertexto e organização do material no MOODLE.

Assim, a ordenação dos módulos em que os hipertextos foram inseridos começa com uma introdução que apresenta os principais fenômenos magnéticos e eletromagnéticos do ponto de vista histórico, segue com a definição de campo magnético em termos da força magnética que age sobre um fio percorrido por corrente elétrica e posteriormente com o tratamento matemático para o cálculo do torque sobre uma espira retangular percorrida por corrente, fechando com a descrição do funcionamento de um motor elétrico simples de corrente contínua.

A figura 02 mostra uma imagem do hiper- 


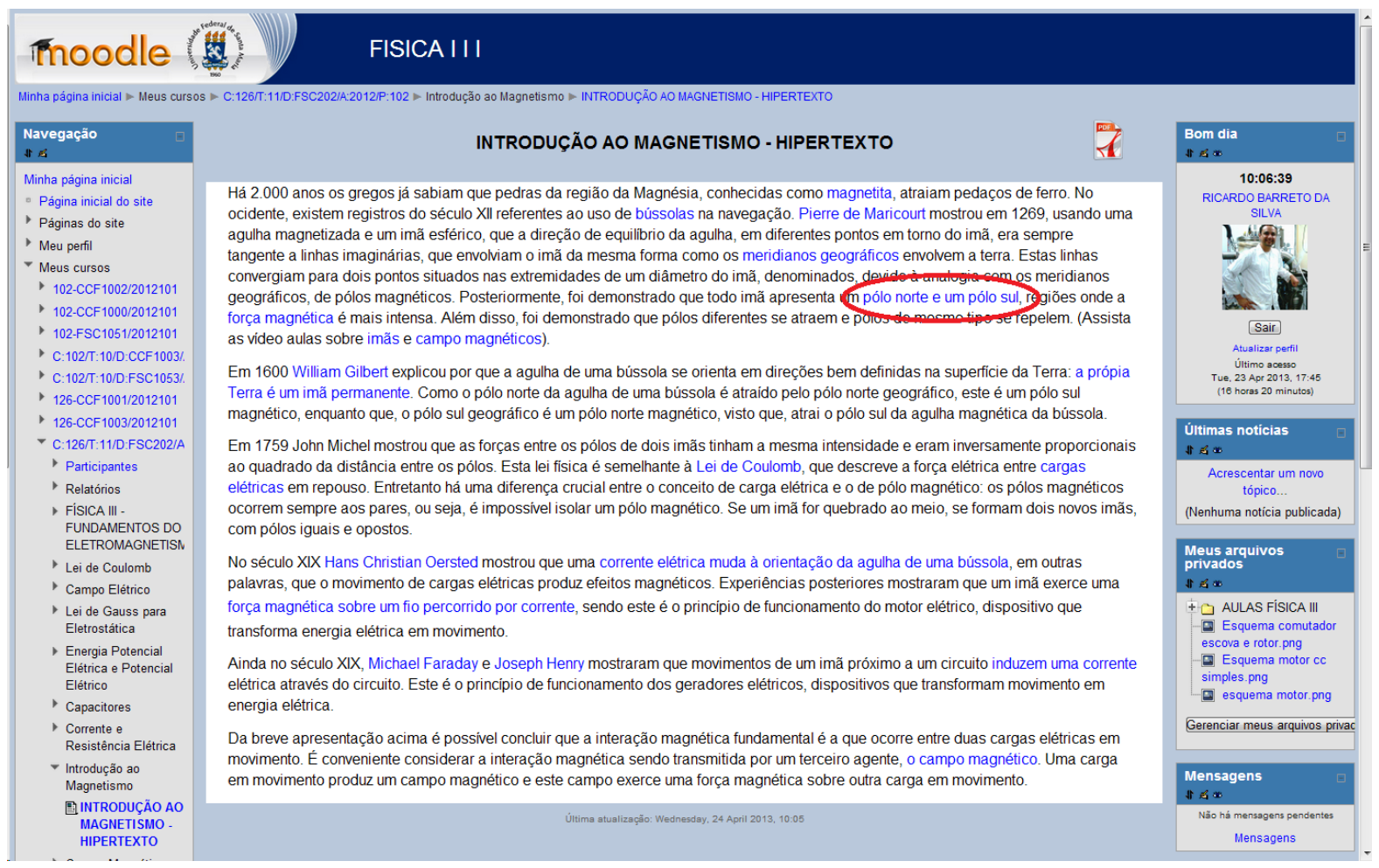

Figura 02 - Imagem do hipertexto Introdução ao Magnetismo. As palavras e expressões em azul são links para páginas da Internet de acesso livre.

\section{YouTube}

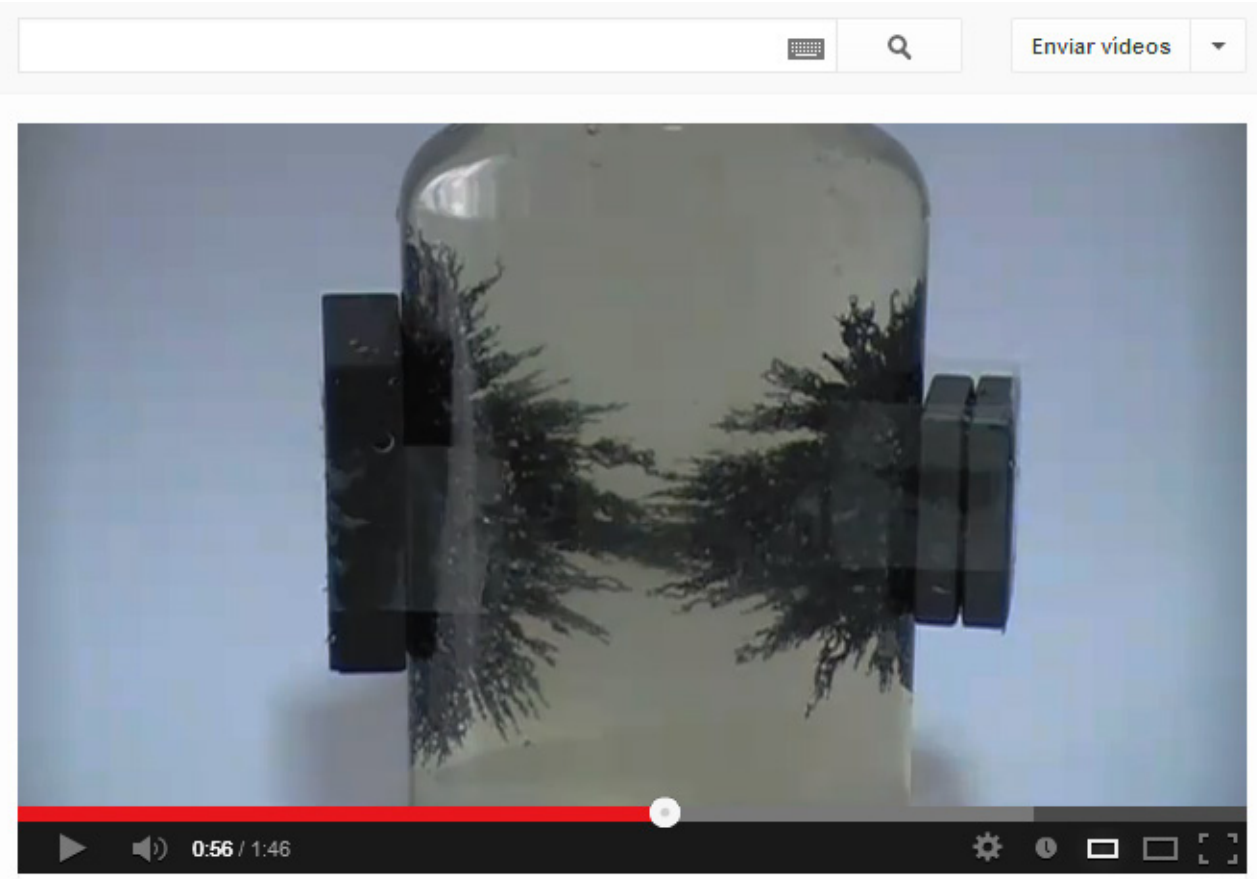

Figura 03 - Imagem de vídeo disponível no Youtube mostrando, através da limalha de ferro mergulhada em óleo vegetal, a configuração do campo magnético quando pólos opostos de dois imãs são aproximados. 
texto Introdução ao Magnetismo, inserido no tópico sete da disciplina. O texto principal foi escrito de forma a apresentar em ordem cronológica algumas das principais descobertas referentes aos fenômenos magnéticos e eletromagnéticos. As palavras e as expressões da cor azul são os links para as páginas da web. Este hipertexto conta com 19 links, dez deles para outros hipertextos, oito para vídeos e um para texto. Entre os vídeos que podem ser acessados cinco são de demonstrações experimentais (visualização tridimensional do campo magnético, forças magnéticas entre imãs, experimento de Oersted, força magnética sobre um fio percorrido por corrente e indução de corrente com um imã), dois são vídeo-aulas (interação entre imãs e o campo magnético gerado por um imã) e um é documentário (o magnetismo da Terra).

Como exemplo de navegação neste hipertexto, afigura 03 mostra a página carregada quando o link "pólo norte e um pólo sul", circulado em vermelho na figura 02 , for acionado. $\mathrm{O}$ vídeo acessado, com duração de 1 min e $46 \mathrm{~s}$, mostra como é possível visualizar o campo magnético produzido na região entre dois pólos opostos. Os fragmentos de ferro, mergulhados no óleo vegetal, em cada ponto da região próxima aos imãs se orientam na direção do campo magnético, materializando o campo magnético numa configuração tridimensional. O material utilizado na produção deste vídeo, limalha de ferro, óleo vegetal, garrafa plástica e imãs, é de baixo custo e de fácil aquisição, de forma que o experimento pode ser facilmente replicado em sala de aula.

A figura 04 mostra a imagem de parte do hipertexto Campo Magnético e Força Magnética. O texto principal apresenta a definição de campo magnético em termos da força magnética que atua sobre uma partícula carregada que se desloca através do campo, a definição da força magnética em termos da força magnética sobre um segmento de fio reto percorrido por corrente; e por fim o cálculo do torque sobre uma espira retangular percorrida por corrente interagindo com um campo magnético uniforme, responsável pelo movimento de rotação do rotor num motor elétrico. Este segundo hipertexto contém 19 links, nove para hipertextos, seis para vídeo-aulas e dois para textos. Como o objetivo deste tópico é o estudo rigoroso das definições de campo, força e torque magnético, bem como de deduções matemáticas das equações que relacionam estas grandezas em diferentes situações, o número de links para aulas online passou de dois para seis, em relação ao hipertexto anterior, cujo conteúdo é de natureza descritiva e o tratamento de cunho qualitativo.

Como exemplo de navegação neste hipertexto, a figura 05 mostra a página carregada quando o link "produto vetorial", circulado em vermelho na figura 04, é acionado. A aula online acessada tem duração de 10 min e 27 s e trata de uma operação

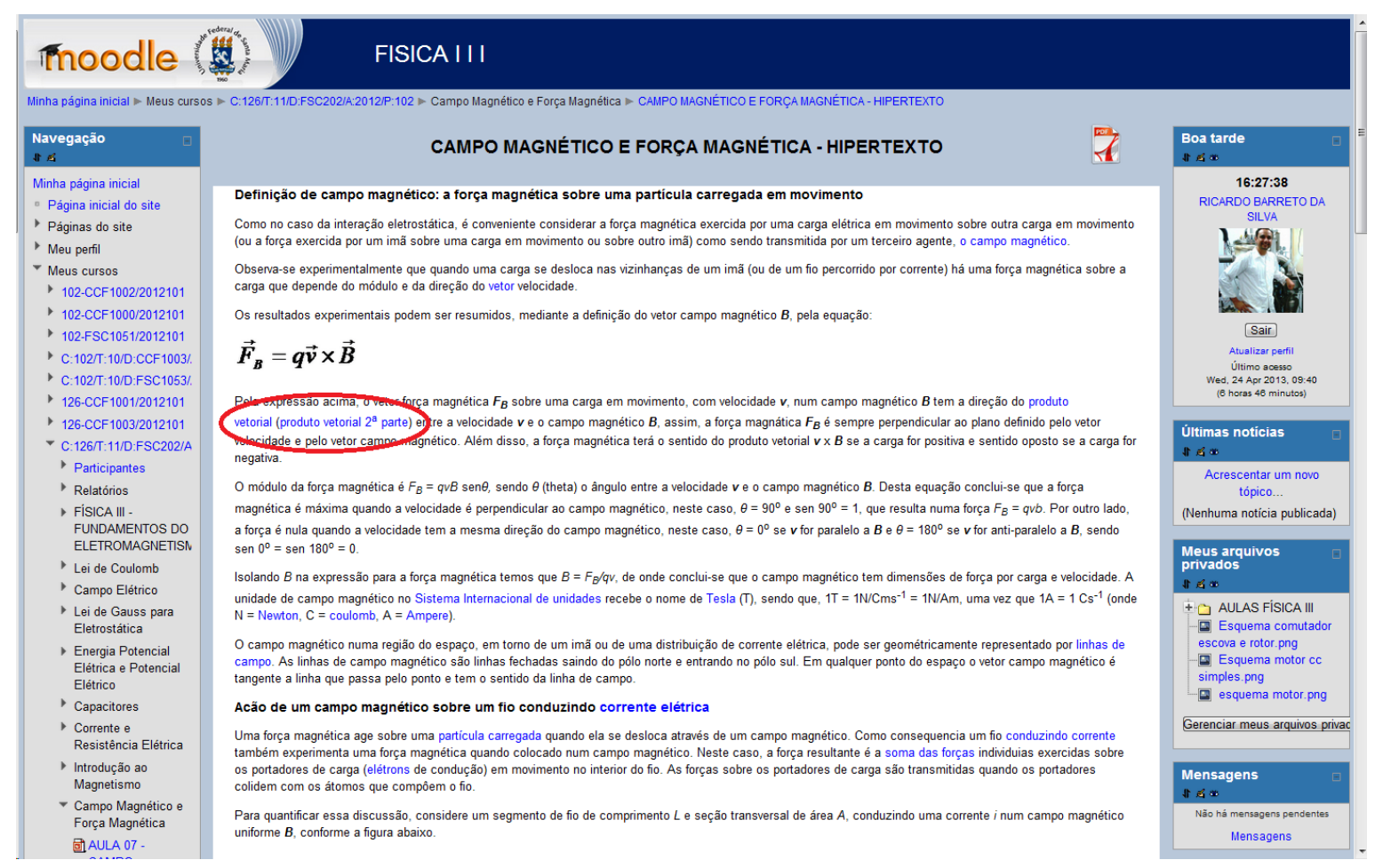

Figura 04 - Imagem de uma parte do hipertexto Campo Magnético e Força Magnética, inserido no módulo oito do curso de Física III. 


\section{KHANACADEMY}

‘ Vídeo anterior: Produto escalar x Produto vetorial

Próximo vídeo: Produto vetorial - parte 2 >

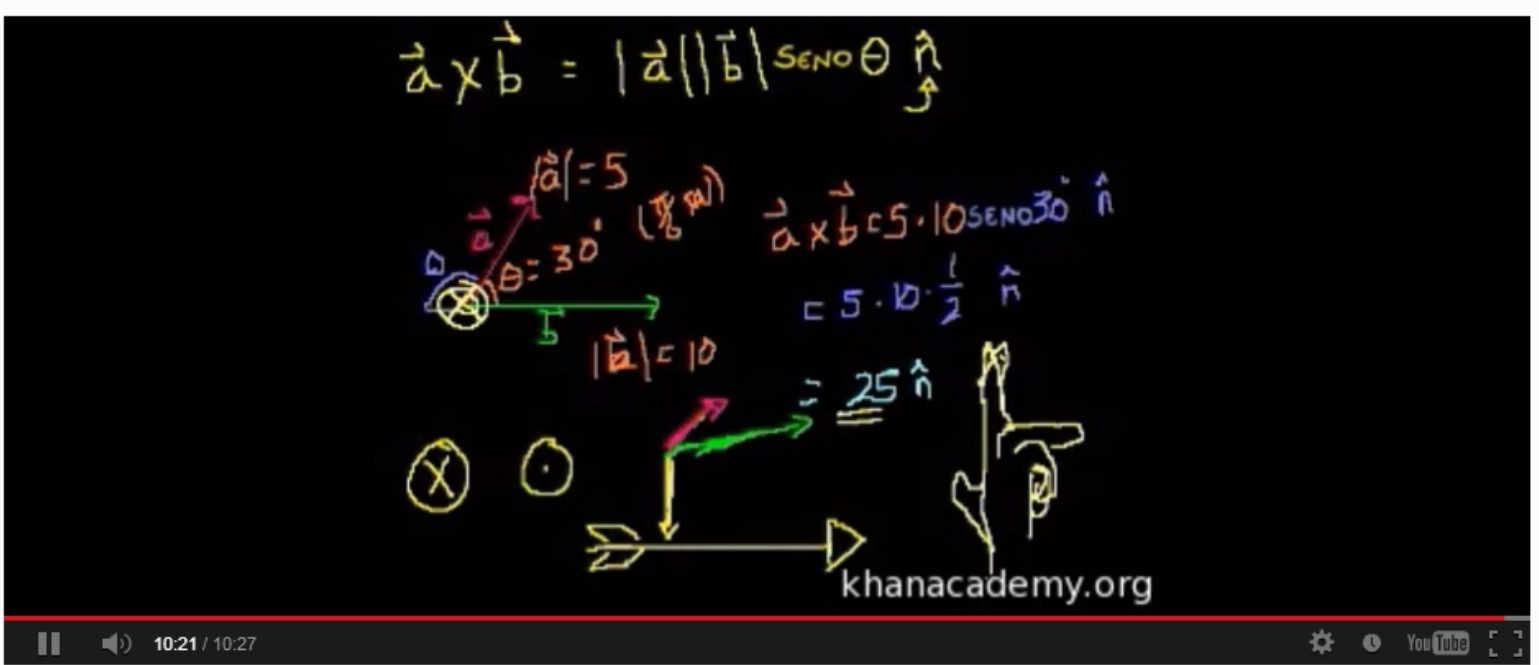

Figura 05 - Imagem da vídeo-aula da Khan Academy Brasil sobre o produto vetorial, disponível na página da Fundação Lemann.

fundamental da álgebra vetorial, o produto vetorial, presente nas equações que definem a força magnética sobre cargas em movimento e a sobre fios percorridos por corrente, bem como na equação do torque magnético sobre uma espira de corrente. Além do cálculo do módulo do produto vetorial, o vídeo explica a regra da mão direita, necessária para a definição da direção e do sentido do vetor resultante do produto entre dois vetores. Embora esta seja uma operação trivial para um estudante experiente, ela pode ser de difícil compreensão para principiantes, muitas vezes numerosos em turmas do terceiro semestre de um curso de graduação em física, o que torna esta possibilidade de consulta bastante útil, mesmo para um curso presencial.

A figura 06 mostra a imagem de parte do hipertexto Motor Elétrico. O texto principal explica o dispositivo, apresentando uma descrição da estrutura mecânica e dos princípios físicos que possibilitam o seu funcionamento. Este hipertexto apresenta oito links com acesso a quatro outros hipertextos, três vídeos e uma imagem. Entre os

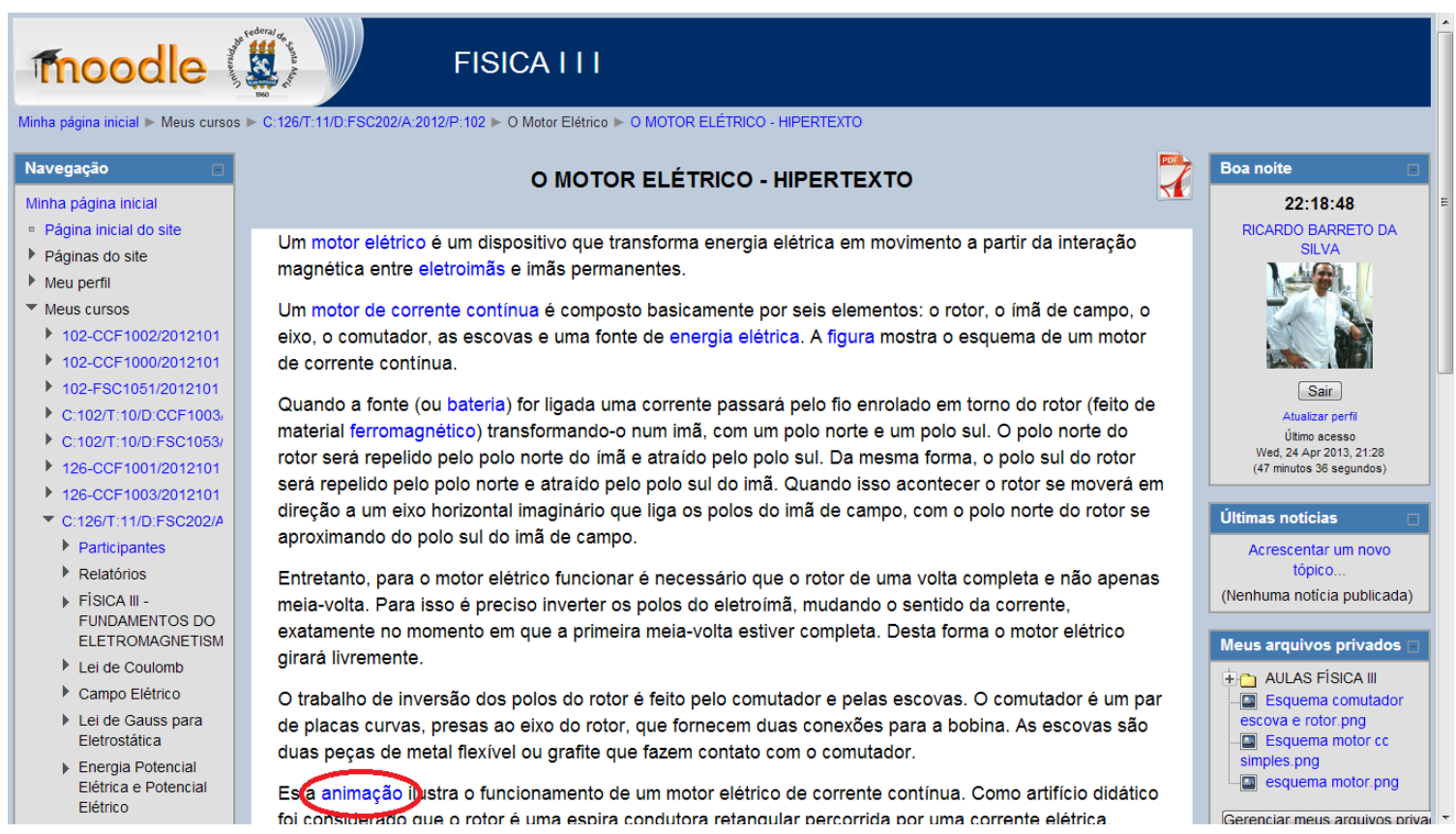

Figura 06 - Imagem de uma parte do hipertexto Campo Magnético e Força Magnética, inserido no módulo nove da disciplina Física III. 


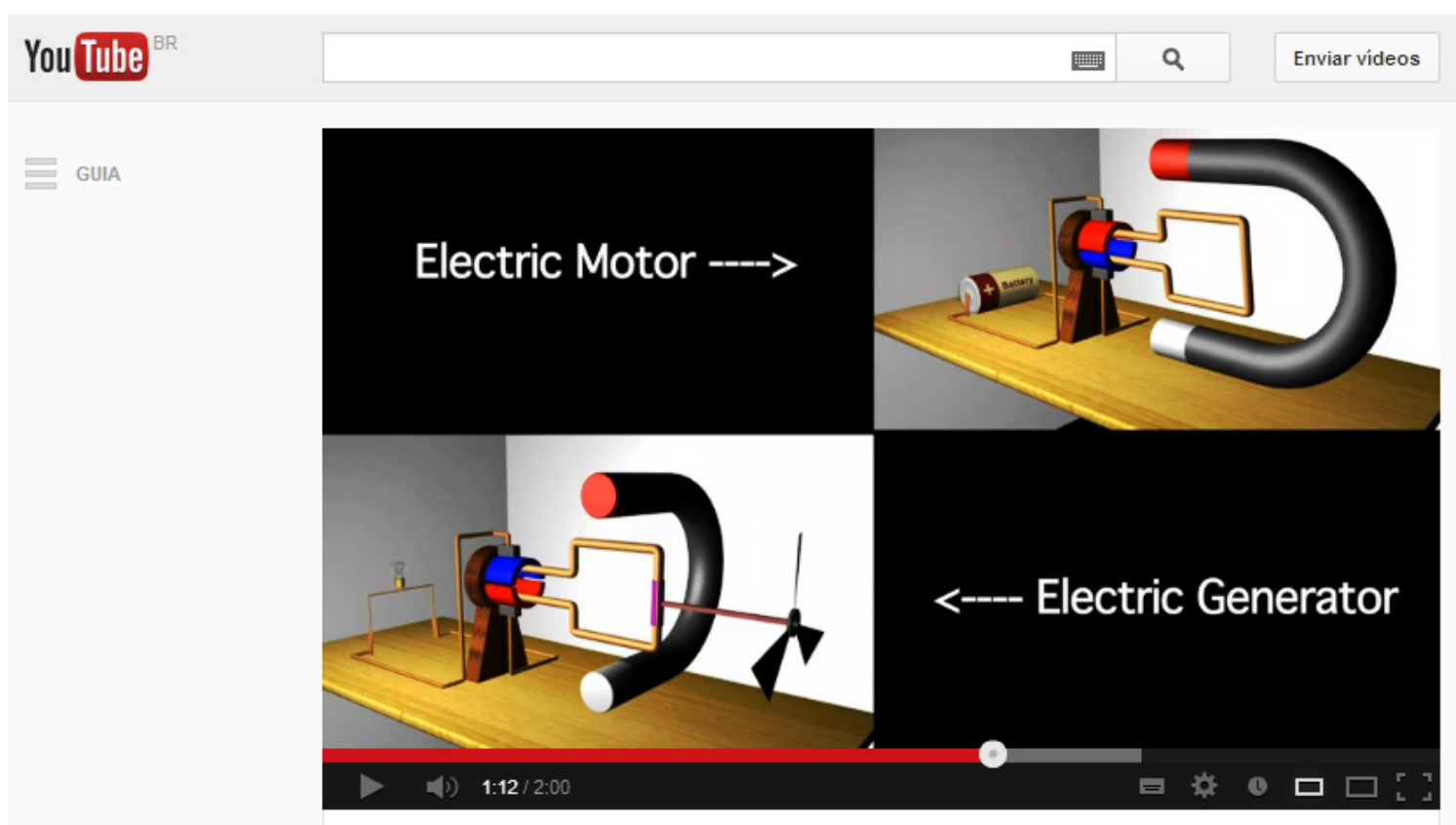

Figura 07 - Imagem de vídeo disponível no Youtube que explica usando uma animação computacional o funcionamento de um motor elétrico de corrente contínua e de um gerador de corrente alternada.

vídeos selecionados, um mostra como fazer um motor elétrico simples enquanto que outro mostra como fazer um eletroímã, ambos utilizando materiais de baixo custo. $\mathrm{O}$ terceiro que pode ser carregado através do link circulado em vermelho na figura 06 explica o motor elétrico de corrente contínua e o gerador de corrente alternada através de uma animação computacional, como mostra a imagem na figura 07. Por questões didáticas, na animação o rotor foi substituído por uma espira retangular. A ênfase do vídeo está na similaridade mecânica e na diferença funcional entre os dispositivos, visto que o motor transforma energia elétrica em cinética enquanto que o gerador transforma energia cinética em elétrica.

A discussão acima ilustra uma possibilidade de organização de recursos educacionais, produzidos na forma de hipertextos, referentes aos conhecimentos de eletromagnetismo necessários para a compreensão de um motor elétrico, que podem ser produzidos e utilizados no ambiente MOODLE. É importante observar que este é um trabalho em andamento, e que as possibilidades do MOODLE no que concerne a criação de atividades de estímulo a processos investigativos e procedimentos avaliativos não foram exploradas neste momento. Além disso, é importante mencionar que esta proposta vai ao encontro do modelo de utilização do MOODLE idealizado pelo NTE e disseminado entre a comunidade universitária através de cursos de capacitação, de acordo com políticas definidas pelas instâncias competentes da UFSM.

\section{Considerações finaIS}

Nesse texto, foram apresentados os resultados preliminares de um projeto cujo objetivo foi desenvolver hipertextos no ambiente MOODLE, envolvendo os temas do eletromagnetismo necessários para a compreensão da montagem e do funcionamento do motor elétrico. Até este ponto, foram produzidos três hipertextos com links para cinco diferentes páginas da web que disponibilizam livremente uma variedade de objetos educacionais, tais como, cadernos digitais, hipertextos, aulas online, vídeos de demonstrações experimentais e de animações computacionais. A descrição do processo de construção desses hipertextos demonstra a potencialidade da web como fonte de objetos educacionais e do MOODLE como instrumento de gerenciamento e produção de hipertextos. Entretanto, é importante mencionar nessa síntese que as possibilidades do MOODLE para o desenvolvimento de atividades, questões, exercícios e avaliações não foram exploradas nesta fase do projeto. Ainda que o material tenha sido utilizado de forma complementar para um curso de eletromagnetismo presencial, o trabalho 
deve ser considerado, até este ponto, como uma apresentação de proposta ${ }^{12}$, que deve ser complementada e cuja eficácia em cursos EAD deverá ser futuramente avaliada através da utilização de métodos qualitativos e quantitativos adequados ${ }^{30}$.

\section{AGRADECIMENTOS:}

o autor gostaria de agradecer a CAPES, a direção do Núcleo de Tecnologia da Informação da UFSM e a coordenação da UAB/UFSM pelo suporte financeiro e técnico.

\section{REFERÊNCIAS}

1. MINISTÉRIO DA EDUCAÇÃO (Brasil). Escassez de professores no Ensino Médio: Propostas estruturais e emergenciais. Brasília, DF, 2007. Disponível em: <http://portal.mec.gov.br/cne/arquivos/pdf/escassez1.pdf> $>$. Acesso em 10 Fevereiro de 2013.

\section{MINISTÉRIO DA EDUCAÇÃO (Brasil).}

Sinopse do Censo dos Profissionais do Magistério da Educação Básica. Brasília, DF, 2006. Disponível em: <http://www.publicacoes.inep.gov.br/detalhes. asp?pub=4063 > . Acesso em 10 Fevereiro de 2013.

3. BRASIL. Decreto $N^{\circ} 5.800$ de 8 de junho de 2006. Dispõe sobre o Sistema Universidade Aberta do Brasil. Disponível em: $<$ http://www.planalto.gov. br/ccivil 03/ ato2004-2006/2006/decreto/d5800. $\underline{\mathrm{htm}}>$. Acesso em 8 Fevereiro de 2013.

4. Disponível em: < http://www.uab.capes.gov.br/>. Acesso em 13 janeiro de 2013.

5. Disponível em: $<$ http://cead.ufsm.br/moodle2 $\mathrm{UAB} / \mathrm{mod} /$ page $/$ view.php?id=16813 $>$. Acesso em 10 março de 2013.

6. Disponível em: <http://nte.ufsm.br/moodle2 $\mathrm{UAB} / \mathrm{mod} / \mathrm{page} / \mathrm{view} . \mathrm{php}$ ?id=16851 $>$. Acesso em 10 março de 2013.

7. Disponível em: < http://w3.ufsm.br/prograd/ ead-ufsm/fis/objetfis.pdf $>$. Acesso em 10 março de 2013.

8. REZENDE, F. \& BARROS, S. A hipermídia e aprendizagem de Ciências: exemplos na área de física. Física na Escola, 6(1), 63, 2005.
9. FIOLHAIS, C.; TRINDADE, J.Física no Computador: o Computador como uma Ferramenta no Ensino e na Aprendizagem das Ciências Físicas. Revista Brasileira de Ensino de Física, 25(3), 259,2003 .

10. BOYCE, W.E.; BRUNSKI, J.B.; CHEN, M.M.; CRAIG, K. FAIRWEATHER, J.A.; HAUS JR.,J.H.; PORTER JR., J.; SIEGMANN, W.L. InteractiveMultimedia Modules in Mathematics, Engineering, and Science. Computers in Physics, 11(2), 151, 1997.

11. ARAUJO, I.S.; VEIT, E.A. Uma revisão da literatura sobre estudos relativos a tecnologias computacionais no ensino de Física. Revista Brasileira de Pesquisa em Educação em Ciências, 4(3), 5, 2004.

12. MELEIRO, A.; GIORDAN, M. Hipermídia no ensino de modelos atômicos. Química Nova na Escola, 10, 17, 1999.

13. REZENDE, F. Desenvolvimento e avaliação de um sistema hipermídia para facilitar a reestruturação conceitual em mecânica básica. Caderno Catarinense de Ensino de Física, 18(2), 197, 2001.

14. LÉVY, P. Cibercultura. São Paulo, SP, Ed. 34, 1999.

15. LÉVY, P. As tecnologias da inteligência: o futuro do pensamento na era da informática. Rio de Janeiro, RJ, Ed. 34, 1993.

16. PEREIRA, J. Sistemas Hipertexto \&Hipermédia: Reflexão, Ensino e Arte. Millenium 25 (2002). Disponível em: http://www.ipv.pt/millenium/Millenium25/default.htm. Acessado em 17 de abril de 2013.

17. HECKLER, V.; SARAIVA, M.F.O.; OLIVEIRA FILHO, K.S. Uso de simuladores, imagens e animações como ferramentas auxiliares no ensino/aprendizagem de óptica. Revista Brasileira de Ensino de Física, 29(2), 267, 2007.

18. PETERS, O. A educação à distância em transição: Tendências e desafios. São Leopoldo, RS, Ed. Unisinos, 2004.

19. Disponível em: <https://moodle.org/>. Acesso em 20 de fevereiro de 2013.

20. DIAS R. A.; LEITE L. S. Educação à distância: da legislação ao pedagógico. Petrópolis, RJ, Ed. Vozes, 2010. 
21. ALVES, L; BRITO, M. O Ambiente MOODLE como Apoio ao Ensino Presencial. Disponível em: < http://www.abed.org.br/congresso2005/por/ pdf/085tcc3.pdf $>$. Acessado em 22 de novembro de 2012.

22. MINISTÉRIO DA EDUCAÇÃO (Brasil). Parâmetros curriculares nacionais: introdução aos parâmetros curriculares nacionais. Brasília, DF, 1997. Disponível em: <http://portal.mec.gov.br/seb/ arquivos/pdf/livro01.pdf>. Acesso em 8 Fevereiro de 2013.

23. MINISTÉRIO DA EDUCAÇÃO (Brasil). PCN+ Ensino Médio: orientações educacionais complementares aos parâmetros curriculares nacionais. Brasília, DF. Disponível em:<http://portal.mec. gov.br/seb/arquivos/pdf/CienciasNatureza.pdf $>$. Acesso em 17 abril de 2013.

24. MOREIRA, M.A.; MASINI, E.F.S. Aprendizagem significativa: a teoria de aprendizagem de David Ausubel. São Paulo, SP, Ed. Centauro, 2006.

25. MORGADO, L. O lugar do hipertexto na aprendizagem: alguns princípios para a sua concepção. Universidade Aberta, Departamento de Ciências da Educação, Lisboa, 1996. Disponível em: <http://www.serprofessoruniversitario.pro. $\mathrm{br} / \mathrm{m} \% \mathrm{C} 3 \% \mathrm{~B} 3 \mathrm{dul}$ os/tecnologia-instrucional/o-lugar-do-hipertexto-na-aprendizagem\#.UavvAtL$\underline{\text { VCSo }}>$. Acesso em 27 de março de 2013.

26. STANTON, N.; STAMMERS, R. B. Learning styles in a non-linear training environment. In: MCALEESE, R. e GREEN, C. (Eds.). Hypertext: state of the art. Oxford, Intellect, 1990. p. 114-120.

27. GUTIERREZ, F. Linguagem total: uma pedagogia dos meios de comunicação. São Paulo, SP, Ed. Summus 1978.

28. MACHADO, D.I.; NARDI, R. Construção de conceitos de física moderna e sobre a natureza da ciência com o suporte hipermídia. Revista Brasileira de Ensino de Física, 28(4), 473, 2006.

29. AUSUBEL, D. P.; NOVAK, J. D.; HANESIAN, H. Psicologia Educacional. Rio de Janeiro, Ed. Interamericana, 1980.

30. MOREIRA, M. Pesquisa em Física: métodos qualitativos e quantitativos. Instituto de Física, UFRGS, Porto Alegre, RS, 2009. 